\title{
Determinants of Antenatal Care Service Utilization during the First Trimester among Pregnant Women in Boke Woreda, Ethiopia: A Facility Based Unmutched Case Control Study
}

\author{
Teklemariam Ergat Yarinbab ${ }^{1 *}$ and Melese Wegayehu Gedle ${ }^{2}$ \\ ${ }^{1}$ Department of Public Health, College of Health Sciences, Mizan-Tepi University, Ethiopia \\ ${ }^{2}$ Department of Reproductive Health, College of Health Sciences, Mekelle University, Ethiopia
}

Submission: May 02, 2018; Published: May 30, 2018

*Corresponding author: Teklemariam Ergat Yarinbab, Department of Public Health, College of Health Sciences, Mizan-Tepi University, MizanAman, Ethiopia, Email: teklemariam36@gmail.com

\begin{abstract}
Background: Antenatal Care (ANC) services utilization during the first trimester is very important for risk identification, and prevention and management of pregnancy-related diseases. However, the ANC services utilization during the first trimester in Ethiopia is very poor. Likewise, there has been no research conducted in Boke Woreda on determinants of ANC services utilization. Therefore, the aim of this study was to identify determinants of ANC services utilization during the first trimester in Boke Woreda, Ethiopia.
\end{abstract}

Methods: A health facility based unmatched case-control study design was conducted in Boke Woreda, Ethiopia. The data was collected using pre-tested and structured questionnaires through interviews. Data analysis was done by SPSS for Windows Version 20.0. Bivariate and multivariate logistic regressions were conducted. P-value $<0.05$ was used to declare statistically significant variables.

Result: All selected pregnant women (339 participants) were interviewed with 100\% response rate. ANC services utilization was associated with maternal age at less than 26 years (AOR=3.87,95\% CI:1.57,9.51), women travelling at lower than 30 minutes to the health facility (AOR=3.26,95\% CI:1.46,7.26), Women who experienced one to two number of pregnancy (AOR=5.01,95\% CI:1.74,14.41), Pregnant women who had zero to two birth before (AOR=3.93,95\% CI:1.35,11.41), and previous ANC service utilization history (AOR=2.52,95\% CI:1.03,6.20). Besides, ANC service utilization was also positively associated with pregnant women who were supported by their family (AOR=3.28, 95\%CI: 1.18 , 9.06), service waiting time at less than 45 minutes (AOR=6.17, 95\% CI: 1.83, 20.73), and pregnant women who were welcomed by health workers (AOR=7.81, 95\% CI: 3.19, 19.09).

Conclusion: Maternal age, travelling time to the health facilities, client welcomed appreciation, maternal knowledge on ANC services, previous service utilization, parity, gravidity, and service waiting time were found to be the determinants of antenatal care services at first trimester. Therefore; Policy makers and stakeholders in the area have to focus their intervention on the identified factors in order to improve the ANC service utilization in the first trimester.

Keywords: Determinants; Antenatal care; First trimester; Boke oreda

\section{Background}

Antenatal Care (ANC) can be defined as the care provided by skilled health-care professionals to pregnant women and adolescent girls in order to ensure the best health conditions for both mother and baby during pregnancy and it is one of the pillars of maternal health services [1]. The components of ANC include; risk identification, prevention and management of pregnancy-related or concurrent diseases and health education and promotion. The goal of ANC is to prevent health problems of pregnant women and to ensure that each newborn child has a good start [2,3].
For provision of antenatal care services like tetanus toxoid immunization, intermittent preventive treatment of malaria, deworming, iron and folic acid is very important before four months of pregnancies. In addition to this, pregnant women should be offered screening for HIV infection and syphilis to reduce mother-to-child transmission. Other intervention that can be linked to early ANC include ultrasound screening to identify congenital abnormalities, provision of information about birth preparedness and complication readiness plan, nutrition, family planning, breastfeeding, and health benefits of delivery with the 
assistance of skilled health provider. Hence, early antenatal care booking is a strong predictor of positive pregnancy outcomes, and has a substantial impact on maternal and child mortality [13].

Globally, annual maternal mortality was reported to be 303,000 in 2015. Developing regions account for approximately $99 \%$ of the global maternal deaths in 2015, with sub-Saharan Africa alone accounting for roughly 66\% $(201,000)$, followed by Southern Asia $21 \%(66,000)$ [3]. It has been estimated that 25 percent of maternal deaths occur during pregnancy, with variability between countries depending on the prevalence of unsafe abortion, violence, and disease in the area. Between a third and a half of maternal deaths are due to causes such as hypertension (pre-eclampsia and eclampsia) and ante partum hemorrhage, which are directly related to inadequate care during pregnancy $[4,5]$.

In Ethiopia many studies indicated that ANC utilization during the first trimester is low and most pregnant women who attend ANC come too late for their first ANC visit ranges from 40 to $60 \%[4,6]$. According to Ethiopian EDHS report; the ANC service coverage was $41 \%$, out of which 18 percent (38\% urban and $14 \%$ rural) of pregnant women were attending ANC services during the first trimester [7].

Some studies reported that maternal education, younger age, marital status, first pregnancy, lower parity, planned pregnancy, history of still birth, previous early antenatal care visit, advice on early antenatal care visit were associated with early antenatal care booking [8-11]. In contrary, there are studies which stated that maternal age, previous utilization of the services and travel time to the health facilities has no association with early antenatal care utilization [6,12-14]. So it needs further investigation in identifying the independent determinants of utilization of antenatal care services during the first trimester.

There is also a gap in information among pregnant mothers in utilization of ANC at first trimester and there is no study conducted in the study area. Therefore, the purpose of this study was to identify determinants of ANC services utilization during the first trimesters in Boke Woreda, Oromia Region, Ethiopia.

\section{Methods}

\section{Study area and period}

The study was conducted in Boke Woreda from February 15 -April 10/2017. Boke Woreda is found in Western Hararghe, Oromia Regional State, Ethiopia. It is located 375 kilometers to the East of Addis Ababa, the capital city of the country. The Woreda had an estimated total population of 141,829 of whom 69,496 are male and 72,333 are females. There were five public Health Centers (HC), 23 health posts and four private clinics. The participants were recruited from all the five Public Health Centers namely Ido-Aroji HC, Boke Tiko HC, Hatura HC, Boke Gudo HC and Arba HC.

\section{Study design}

Facility based unmatched case control study was conducted. Cases and controls were selected based on the eligibility criteria.

i. Cases: Pregnant women who visited ANC at less than four months of pregnancy.

ii. Controls: Pregnant women who were attending ANC at greater than or equal to four months of pregnancy. In both cases and controls the first ANC visit was considered for current pregnancy.

\section{Eligibility criteria}

\section{Inclusion criteria}

i. For cases and controls: Pregnant women who had interest to respond the questionnaires and fulfilled the definition of cases and controls were included in the study.

\section{Exclusion criteria}

ii. For cases and controls: Pregnant women who were unable to respond and who were not fulfilling the definition of cases and controls were excluded from the study.

\section{Sample size determination \& sampling procedure}

The sample size was calculated by taking educational level of pregnant women as the major determinant of ANC services utilization which gives large sample size; $32.9 \%$ proportion of exposure among cases and $31.2 \%$ proportion of exposure among controls [8,11]. 2 odds ratio to detect case (OR), 80\% power and $95 \%$ confidence level and ratio of cases to controls was 1:2 and $10 \%$ non-response rate. The calculated sample size was 339 (113 cases and 226 controls).

Those women fulfilling the inclusion criteria were recruited until the required sample size was achieved. For each case two consecutive controls were selected among the pregnant women who were attending the ANC services during the first trimester of the last four months.

\section{Data quality control}

The questionnaires were translated from English into the local language (Afan-Oromo) \& vice versa. A pre-test was conducted on $5 \%$ of the sample. Data collectors were trained on how to conduct the data. Daily supervision was held at all health centers by field supervisors and the investigator. Data collectors were enabled to rectify incomplete and inconsistent data by supervisors at the time of data collection. Supervisors used to check all procedures and completeness of formats randomly. The collected data were rechecked before data entry.

\section{Data collection tools and procedures}

The data was collected using pre-tested structured questionnaire. The study subjects were selected in case to control (1:2) ratio. Five BSc degree holder nurses, who were not working in the department of maternity, were participated in 
the data collection. Two supervisors were participated from the adjacent woreda health office. Half a day orientation was given to the data collectors and supervisors on the data collection tools and procedures by the principal investigator.

\section{Data processing and analysis}

Data were edited, coded and entered in to Epi info version 3.5.1 and then exported to and analyzed by SPSS windows version 20. Frequencies and percentages of different variables were computed to summarize the data. Bivariate logistic regression model was fitted as a primary method of analysis. Based on the findings of bivariate analysis, variables having $\mathrm{p}<0.2$ were entered into multivariate logistic regression analysis using the forward LR method. Finally, $\mathrm{P}<0.05$ in multivariate analysis was used to identify confounding factors and determinants of early ANC utilization. The fitness of logistic regression models was assessed using the Hosmer-Leme show statistic and multicollinearity problem was also checked and the variables which had high multicollinearity problems were eliminated from the model.

\section{Ethical approval and consent to participate}

Before the actual data collection; the proposal was presented to Mekelle University, School of Public Health, and then ethical clearance letter was obtained from Institutional Review Board (IRB) of College of Health Sciences. The participants were well informed about the purposes of the study, and oral consents were obtained accordingly. The participants' rights to refuse or withdraw from participating in the study and confidentiality issues were considered.

\section{Operational definitions and definitions of terms}

i. Good knowledge: Those who knew $60 \%$ or above from six knowledge measuring questions.

Poor Knowledge: Those who knew less than $60 \%$ from six knowledge measuring questions [15].

ii. Timely attending ANC: Attending ANC before 16 weeks of gestational age for current pregnancies.

iii. Lately attending ANC: Pregnant women who never came before 16 weeks of gestational age and Attending ANC within four to nine months of pregnancy for current pregnancies.

iv. Client welcomed appreciation: positive relationship between pregnant women and health care providers, measured as they were hospitalized or not by the health care provider for the provision of ANC services at the health facilities.

v. Family support: opinion, financial, and other physical support from family members such as husband, mother, sister etc. during ANC service follow up.

\section{Results}

\section{Socio-demographic characteristics}

The total numbers of study participants was three hundred thirty nine (113 cases and 226 controls) with $100 \%$ response rate. The mean age for cases and controls were 22.4(+SD4.15) and 28.04(+SD 5.08), respectively (Table 1$)$.

Table 1: Socio-demographic characteristics of the respondents in Boke Woreda, Oromia Region, Ethiopia, 2017.

\begin{tabular}{|c|c|c|c|c|}
\hline \multirow{2}{*}{ Variables } & \multirow{2}{*}{ Categories } & \multicolumn{3}{|c|}{ Attended ANC before 4 Months of Gestation } \\
\hline & & Yes $(\%)$ cases $=113$ & No $(\%)$ Controls $=226$ & Total (\%) \\
\hline \multirow{2}{*}{ Maternal age } & $<26$ years & $88(77.9)$ & $74(32.7)$ & $162(47.8)$ \\
\hline & $>=26$ years & $25(22.1)$ & $152(67.3)$ & $177(52.2)$ \\
\hline \multirow{2}{*}{ Ethnicity } & Oromo & $103(91.15)$ & $216(95.56)$ & $319(94.1)$ \\
\hline & Others ${ }^{1}$ & $10(8.8)$ & $10(4.4)$ & $20(5.9)$ \\
\hline \multirow{3}{*}{ Religion } & Muslim & $97(85.84)$ & 201(88.93) & 298(87.9) \\
\hline & Orthodox & $13(11.5)$ & 18(7.96) & $31(9.1)$ \\
\hline & Others ${ }^{2}$ & $3(2.66)$ & $7(3.11)$ & $10(3.0)$ \\
\hline \multirow{4}{*}{ Educational status } & No formal education & $26(23)$ & $132(58.4)$ & $158(46.6)$ \\
\hline & Primary education & $41(36.28)$ & $67(29.64)$ & 108(31.9) \\
\hline & Secondary education & $24(22)$ & $16(7)$ & $40(11.8)$ \\
\hline & College and above & $22(18.72)$ & $11(4.96)$ & $33(9.7)$ \\
\hline \multirow{3}{*}{ Occupational status } & Employed & $20(17.69)$ & $11(4.86)$ & $31(9.1)$ \\
\hline & Merchant & $20(17.69)$ & 28(12.38) & $48(14.2)$ \\
\hline & House wife & $73(64.62)$ & $187(82.47)$ & $260(76.7)$ \\
\hline \multirow{2}{*}{ HHs monthly income } & $<1000$ Birr & $52(46.0)$ & 184(81.41) & $236(69.6)$ \\
\hline & $>=1000$ Birr & $61(55.0)$ & $42(18.59)$ & $103(30.4)$ \\
\hline
\end{tabular}




\section{Current Trends in Biomedical Engineering \& Biosciences}

\begin{tabular}{|c|c|c|c|c|}
\hline \multirow{2}{*}{ Transportation } & On foot & $93(82.3)$ & 192(84.95) & $285(84.1)$ \\
\cline { 2 - 5 } & By car & $20(17.7)$ & $34(15.05)$ & $54(15.9)$ \\
\hline \multirow{2}{*}{ Travel time in minutes? } & $<=30$ & $77(68.14)$ & $61(26.99)$ & $138(40.7)$ \\
\cline { 2 - 5 } & $>30$ & $36(31.86)$ & $165(73.01)$ & $201(59.3)$ \\
\hline
\end{tabular}

\section{Reproductive Health Factors}

Seventy four $(65.5 \%)$ of cases and thirty nine $(17.25 \%)$ of controls had less than or equal to two pregnancies while thirty nine (34.5\%) of cases and 187(82.7\%) of controls had three and more number of pregnancies prior to current pregnancies. Large proportion of cases and controls had no history of still births which is one hundred ten (97.3\%) of cases and 196(86.7\%) of controls respectively (Table 2).

Table 2: Reproductive health factors of respondents in Boke Woreda, Oromia Region, Ethiopia, 2017.

\begin{tabular}{|c|c|c|c|c|}
\hline \multirow{2}{*}{ Variables } & \multirow{2}{*}{ Categories } & \multicolumn{3}{|c|}{ Attended ANC before 4 Months of Gestation? } \\
\hline & & Yes (\%) & No (\%) & Total (\%) \\
\hline \multirow{2}{*}{ Number of pregnancies } & 2-Jan & $74(65.48)$ & $39(17.25)$ & 113(33.3) \\
\hline & $>=3$ & $39(34.52)$ & $187(82.75)$ & $226(66.7)$ \\
\hline \multirow{2}{*}{ History of abortion } & Yes & $12(10.62)$ & $30(13.27)$ & $42(12.4)$ \\
\hline & No & $101(89.38)$ & $196(86.73)$ & $297(87.6)$ \\
\hline \multirow{2}{*}{ History of still birth } & Yes & $3(2.65)$ & $22(9.73)$ & $25(7.4)$ \\
\hline & No & $110(97.35)$ & $204(90.27)$ & $314(92.6)$ \\
\hline \multirow{2}{*}{ Number of live births } & $0-2$ & $102(90.3)$ & $87(38.5)$ & $189(55.8)$ \\
\hline & $>=3$ & $11(9.7)$ & $139(61.5)$ & $150(44.2)$ \\
\hline \multirow{2}{*}{ Place of last delivery } & Home & $14(12.39)$ & $123(54.42)$ & $137(40.4)$ \\
\hline & Health Inst & $57(50.44)$ & $87(38.49)$ & $144(42.5)$ \\
\hline \multirow{2}{*}{ Pregnancy illness } & Yes & $50(44.25)$ & $109(48.23)$ & $159(46.9)$ \\
\hline & No & $63(55.75)$ & $117(51.77)$ & $180(53.1)$ \\
\hline \multirow{2}{*}{ Modes of last delivery } & NVD & $69(61.06)$ & $204(90.26)$ & $273(80.5)$ \\
\hline & CS & $2(1.77)$ & $6(2.66)$ & $8(2.4)$ \\
\hline \multirow{2}{*}{$\begin{array}{l}\text { Recognition of current } \\
\text { pregnancy }\end{array}$} & 1-3month & $96(84.95)$ & $123(54.42)$ & $219(64.6)$ \\
\hline & $>=4$ month & $17(15.05)$ & $103(45.58)$ & $120(35.4)$ \\
\hline
\end{tabular}

\section{Reasons for attending ANC services}

From the total of antenatal care services attendants, fortytwo (37.2\%) of cases and fifty-three $(23.45 \%)$ of controls were responded as it is the right time to visit. On the other hand, thirty- one $(27.4 \%)$ of cases and sixty $(26.5 \%)$ of controls responded as they visited because of sickness whilst thirty-three $(29.2 \%)$ of cases and 51(22.57\%) of controls said it was for pregnancy checkup (Figure 1).

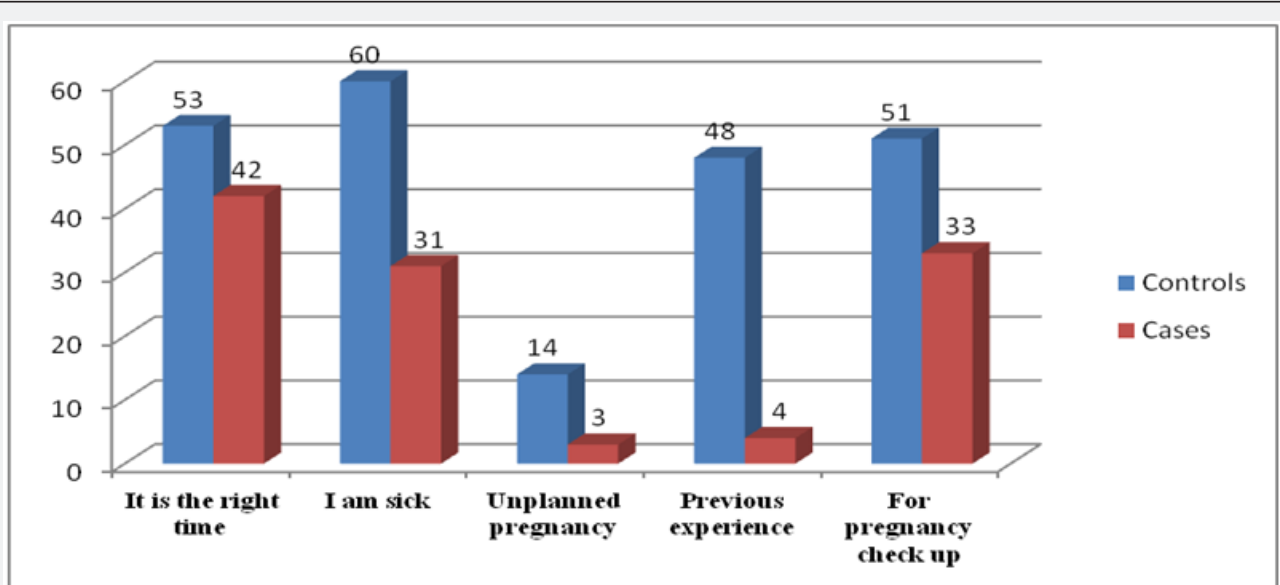

Figure 1: Reasons for attending antenatal care services among pregnant women in Boke Woreda, Oromia Region, Ethiopia, 2017. 


\section{Determinants of ANC service utilization}

The odds of pregnant women at less than 26 years old were about 4 times (AOR=3.86, 95\% CI: 1.57,9.51) more likely to use ANC services during the first trimester than pregnant women who were at age greater than or equal to 26 years of age groups. Similarly, the odds of pregnant women travelling at lower than 30 minutes were 3 times (AOR=3.26, 95\% CI: 1.46, 7.26) more likely to use ANC service during the first trimester than women who travel at 30 minutes and above.

The odds of ANC services use in the first trimester for pregnant women who recognized their current pregnancy within 1-3 months were 7 times (AOR=7.32, 95\% CI: 2.65, 20.24) more likely than their counterparts. Besides, the odds of pregnant women who had good knowledge were 10 times (AOR=9.76, $95 \%$ CI: $3.80,25.09$ ) more likely to use ANC services during the first trimester than those who had poor knowledge about the importance of the services. The odds of pregnant women who had experiences of ANC utilization, on the other hand, were 3 times (AOR=2.52, 95\% CI: 1.03-6.20) more likely to use ANC services than those who had no experiences.

The odds of pregnant women who supported by their families were 3 times (AOR=3.27, 95\% CI: 1.18, 9.06) more likely to use ANC during first trimester than those who were not supported, where as the odds of pregnant women who wait services at less than 45 minutes were 6 times (AOR=6.17, 95\% CI: 1.84, 20.73) higher to use ANC services than those who wait services for 45 minutes and more (Table $3 \& 4$ ).

Table 3: Determinants of ANC utilization during the first trimester in Boke Woreda, Oromia Region, Ethiopia, 2017.

\begin{tabular}{|c|c|c|c|c|c|}
\hline \multirow[t]{2}{*}{ Variables } & \multirow[t]{2}{*}{ Categories } & \multicolumn{2}{|c|}{$\begin{array}{l}\text { Attended ANC Before } 4 \text { Months of } \\
\text { Gestation? }\end{array}$} & \multirow[t]{2}{*}{$\operatorname{COR}(95 \% \mathrm{CI})$} & \multirow[t]{2}{*}{ AOR(95\%CI) } \\
\hline & & Yes (\%) & No (\%) & & \\
\hline \multirow{4}{*}{ Age category } & $<26$ years & 88(77.9) & $74(32.7)$ & $7.23(4.28-12.21)$ & $3.869(1.57-9.51)^{* *}$ \\
\hline & $>=26$ years & $25(22.1)$ & $152(67.3)$ & 1 & 1 \\
\hline & No formal edu & $26(23)$ & $132(58.4)$ & 1 & 1 \\
\hline & Primary educ & $41(36.3)$ & $67(29.64)$ & $3.107(1.75-5.51)^{*}$ & $0.870(.324-2.335)$ \\
\hline \multirow{2}{*}{ Educational status } & Secondary edu & $24(22)$ & $16(7)$ & $7.62(3.56-16.28)^{*}$ & $0.405(0.094-1.744)$ \\
\hline & College \& above & $22(18.7)$ & $11(4.96)$ & $10.15(4.39-23.45)^{*}$ & $1.236(0.252-6.053)$ \\
\hline \multirow{2}{*}{ HHs monthly income } & $<1000$ Birr & $52(46.0)$ & $184(81.4)$ & 1 & 1 \\
\hline & >=1000Birr & $61(53.8)$ & $42(18.59)$ & $5.139(3.12-8.47)$ & $1.45(0.49-4.23)$ \\
\hline \multirow{2}{*}{$\begin{array}{l}\text { Travel time in } \\
\text { minutes? }\end{array}$} & $<=30$ & $77(68.1)$ & $61(26.99)$ & $5.79(3.53-9.47)$ & $3.26(1.46-7.26)^{* *}$ \\
\hline & $>30$ & $36(31.9)$ & $165(73.0)$ & 1 & 1 \\
\hline \multirow{2}{*}{ Gravidity } & 2-Jan & $74(65.48)$ & $39(17.25)$ & $9.098(5.41-15.29)$ & $5.014(1.74-14.4)^{* *}$ \\
\hline & $>=3$ & $39(34.52)$ & $187(82.7)$ & 1 & 1 \\
\hline \multirow{2}{*}{ Still birth } & Yes & $3(2.65)$ & $22(9.73)$ & 1 & 1 \\
\hline & No & $110(97.35)$ & $204(90.27)$ & $3.954(1.158-13.506)^{*}$ & $1.726(.317-9.400)$ \\
\hline \multirow{2}{*}{ Parity } & $0-2$ births & $102(90.3)$ & $87(38.5)$ & $14.81(7.53-29.16)$ & $3.93(1.35-11.41)^{* *}$ \\
\hline & $>=3$ births & $11(9.7)$ & $139(61.5)$ & 1 & 1 \\
\hline \multirow{2}{*}{ Place of last delivery? } & Home & $14(12.39)$ & $123(54.4)$ & 1 & 1 \\
\hline & Health inst & $57(50.44)$ & $87(38.49)$ & $5.76(3.017-10.98)$ & $1.082(0.335-3.485)$ \\
\hline \multirow{2}{*}{$\begin{array}{l}\text { Recognition of } \\
\text { current pregnancy }\end{array}$} & 1-3months & $96(84.95)$ & $123(54.4)$ & $4.73(2.65-8.43)$ & $7.33(2.65-20.24)^{* *}$ \\
\hline & $>=4$ months & $17(15.05)$ & $103(45.5)$ & 1 & 1 \\
\hline
\end{tabular}

*Significant in COR at $p$ value $<0.05$

**Significant in AOR; 1-reference category

Table 4: Determinants of ANC utilization during the first trimester in Boke Woreda, Oromia Region, Ethiopia, 2017.

\begin{tabular}{|c|c|c|c|c|}
\hline \multirow{2}{*}{ Variables } & \multirow{2}{*}{ Categories } & \multicolumn{2}{|c|}{$\begin{array}{c}\text { Attended ANC Before 4 Months of } \\
\text { Gestation? }\end{array}$} & \multirow{2}{*}{ COR(95\%CI) } \\
\cline { 2 - 5 } & & Yes (\%) & No (\%) & $7.28(4.12-12.85)$ \\
\hline \multirow{2}{*}{$\begin{array}{c}\text { Knowledge about } \\
\text { ANC services? }\end{array}$} & Good & $95(84.1)$ & $95(42)$ & 1 \\
\hline \multirow{2}{*}{$\begin{array}{c}\text { Previous ANC } \\
\text { utilization? }\end{array}$} & Poor & $18(15.9)$ & $131(58)$ & $1.76(3.80-25.09)^{* *}$ \\
\cline { 2 - 5 } & Yes & $64(56.64)$ & $96(42.48)$ & $2.52(1.03-6.20)^{* *}$ \\
\hline
\end{tabular}


Current Trends in Biomedical Engineering \& Biosciences

\begin{tabular}{|c|c|c|c|c|c|}
\hline \multirow{2}{*}{$\begin{array}{l}\text { ANC services waiting } \\
\text { time in minutes? }\end{array}$} & $<45$ & $107(94.9)$ & $135(59.7)$ & $12.02(5.06-28.53)$ & $6.17(1.83-20.73)^{* *}$ \\
\hline & $>=45$ & $6(5.31)$ & $91(40.27)$ & 1 & 1 \\
\hline \multirow{2}{*}{$\begin{array}{l}\text { Is this pregnancy } \\
\text { planned? }\end{array}$} & Yes & $95(84.07)$ & $142(62.8)$ & $3.122(1.76-5.53)^{*}$ & $0.986(.327-2.977)$ \\
\hline & No & $18(15.93)$ & $84(37.17)$ & 1 & 1 \\
\hline \multirow{2}{*}{$\begin{array}{c}\text { Family support for } \\
\text { ANC visit? }\end{array}$} & Yes & $101(89.4)$ & $139(61.5)$ & $5.80(2.95-11.42)^{*}$ & $3.277(1.18-9.06)$ \\
\hline & No & $12(10.6)$ & $87(38.5)$ & 1 & 1 \\
\hline \multirow{2}{*}{$\begin{array}{l}\text { Is the health workers } \\
\text { welcomed you? }\end{array}$} & Yes & $88(77.87)$ & $71(31.41)$ & 7.68(4.54-12.99) & $7.81(3.19-19.09)^{* *}$ \\
\hline & No & $25(22.13)$ & $155(68.6)$ & 1 & 1 \\
\hline \multirow{2}{*}{$\begin{array}{c}\text { Who made the last } \\
\text { decision to initiate } \\
\text { ANC visit? }\end{array}$} & Together & $86(76.11)$ & $103(45.6)$ & $3.804(2.29-6.30)$ & $0.758(.187-3.069)$ \\
\hline & my self & $27(23.89)$ & $123(54.4)$ & 1 & 1 \\
\hline \multirow{3}{*}{$\begin{array}{l}\text { Accompanied person } \\
\text { to ANC visit? }\end{array}$} & Husband & $49(43.36)$ & $44(19.47)$ & $3.541(2.11-5.93)$ & $0.768(.278-2.121)$ \\
\hline & Others & $14(12.39)$ & $23(10.18)$ & $1.936(.927-4.043)$ & $0.976(.219-4.349)$ \\
\hline & Alone & $50(44.25)$ & $159(70.3)$ & 1 & 1 \\
\hline
\end{tabular}

*Significant in COR at $p$ value $<0.05$;* Significant in AOR; 1-reference category

\section{Discussion}

The study focused on the important determinants of ANC utilization during the first trimester. It revealed that pregnant women with the age of less than 26 years were more likely to use ANC services at first trimester than those at age of greater than or equal to 26 years old. This finding is in line with the study findings in Ethiopia and Benin which revealed that ANC early utilization is about 2-4 times more common among age of less than 26 years than their counter parts $[7,8,16,17]$. The possible reason may be existence of more fear in younger women for fist pregnancy and their better health seeking behavior due to their access to health information. However, this finding is inconsistent with the findings of a study in Hadiya zone, Ethiopia, and a finding from Meta-analysis in middle income countries [18-20]. The possible reasons may be lack of experiences in the use of ANC services among younger women and cultural factors.

Women who traveled less than 30 minutes to the health facility were more likely to use ANC at first trimester than those who travel at 30 minutes and above. This finding is consistent with the findings from a cross sectional study in Assosa District, Ethiopia [19] whilst it is in contrast with a study finding in Kembata Tembaro Zone, Ethiopia [14,20].

Gravidity and Parity also showed a strong association with antenatal care utilization. This finding is in line with the findings from cross sectional studies in Holeta town, Ethiopia, and Benin $[9,16]$. This may be due to the fact that women with more pregnancy and parity prior to current pregnancies have already developed confidences that modern health care is not necessary at the first trimester.

Family support was found to be associated with ANC utilization. Accordingly, pregnant women who supported by their family were more likely to use ANC services during the first trimester than those who were not supported. This result is in line with the study findings in Holeta Town and Benishangul Gumuz, Ethiopia $[9,19]$.
Besides, waiting time and health care providers welcomed appreciation showed a significant association with ANC utilization. It revealed that pregnant women who spent less than 45 minutes to get a service were more likely to use ANC during the first trimester than those spent more time. This indicates that long waiting time for a service at the facilities is a barrier to initiate ANC utilization in recommended period. This finding is in line with a study conducted in Holeta town which revealed that waiting for a long time of the services may hinder early ANC service utilization [9]. Pregnant women welcomed by health care providers, on the other hand, showed more likelihood of ANC utilization. This is in line with the study findings in Benin [16]. This indicates that the pregnant women who were more welcomed and had positive relationship with the health care providers were more likely to use ANC services earlier.

\section{Conclusion}

The study revealed that age at pregnancy, travel time to the health facility, number of pregnancy, number of births, early recognition of current pregnancy, services waiting time, presence of family support, knowledge about the ANC services, previous antenatal care service use, and client welcomed appreciation were the most important determinants of antenatal care service utilization during the first trimester.

\section{Recommendations}

FMOH and RHB should design and implement specific behavioral change communication program to improve clienthealth care provider's relationship. Zonal and Woreda health offices should focus on improving women's knowledge on ANC service utilization in the first trimester through adult learning program. Health workers and Health extension workers should take an opportunity to encourage mothers to start their first antenatal care visit before four months of pregnancy. Health care providers should also carry out community based intervention to improve communication and support through facilitated participatory learning and actions cycles with women groups. 
Families should be welcomed to attend an ANC session with the pregnant woman. WDAs and community leaders should be capacitated and strengthen in participating of early antenatal care service utilization. Further study is needed to assess the effect of quality of the services on ANC utilization during the first trimester.

\section{Authors' Contribution}

Both TE and MW took the role from conception to design, wrote down the proposal, supervised the data collection process, conducted the final analysis and report writing, and drafted the manuscript. Both authors critically reviewed and approved the final manuscript.

\section{Acknowledgment}

First of all, our deepest gratitude and appreciation goes to School of Public Health, College of Health Sciences, Mekelle University. We would also like to extend our gratitude to Boke woreda health office staffs and the health center staffs for their cooperation in the data collection. Finally, our great appreciation goes to the data collectors and supervisors who participated in the study.

\section{References}

1. Global Health Observator (WHO) (2011) Antenatal care-situations and trends.

2. BanKi Moon G (2015) Millennium Development Goals Report, United Nations, New York, USA.

3. Trends in maternal mortality (2015) 1990 to 2015, Estimates by WHO, UNICEF, UNFPA, the World Bank and the United Nations Population Division.

4. Bahilu T (2009) Factors affecting antenatal care utilization in yem special woreda, southwestern Ethiopia. Ethiop Journal Health Sci 19(45).

5. Ornella L, Seipati M, Patricia G, Munjanja S (2016) Antenatal care for a positive pregnancy experience; Opportunities for Africa's Newborns. pp. $51-55$

6. Tariku A, Melkamu Y, Kebede Z (2010) Previous utilization of service does not improve timely booking in antenatal care: Cross sectional study on timing of antenatal care booking at public health facilities in Addis Ababa. Ethiop J Health dev 24(3): 226-233.

7. Central Statistical Agency [Ethiopia] (2014) Ethiopia Mini Demographic and Health Survey. Addis Ababa, Ethiopia, p. 44.
8. Belayneh T, Adefris M, Andargie G (2014) Previous early antenatal serviceutilization improves timely booking: cross-sectional study at university of gondar hospital, Northwest Ethiopia.

9. Birmeta K, Dibaba Y, Woldeyohannes D (2013) Determinants of maternal health care utilization in Holeta town, central Ethiopia. BMC Health Serv Res 13: 256-258.

10. Cresswell J, Yu G, B H, Morris J, Jamal F (2013) Predictors of the timing of initiation of antenatal care in an ethnically diverse urban cohort in the UK. BMC Pregnancy Childbirth 13: 103.

11. Hamdela B, Godebo G, Gebre T (2015) Predictors of early antenatal care booking in government health facilities of Hossana town, Hadiya zone, south Ethiopia: unmatched case control study. J AIDS Clin Res 6: 521.

12. Zeine A, Mirkuzie W, Shimeles 0 (2010) Factors influencing antenatal care service utilization in Hadiya Zone. Ethiop J Health Sci 20(2).

13. Temesgen WG, Solomon MW, Abdella AA (2014) Timing and factors associated with first antenatal care booking among pregnant mothers in Gondar Town; North West Ethiopia. BMC Pregnancy and Childbirth 14(287).

14. Tesfalidet T, Balcha B (2014) Factors associated with late initiation of antenatal care among pregnant women attending antenatal clinic at public health centers in Kembata Tembaro Zone, Southern Ethiopia. Science, Technology and Arts Research Journal 3(2): 108-115.

15. Yang Y (2010) Factors affecting the utilization of antenatal care services among women in Kham District, Xiengkhouang Province, Lao PDR. Nagoya J Med Sci 72(1-2): 23-33.

16. Ouendo E, Sossa JC, Saizonou J, Guedegbe CCJ, Mongbo AV, et al. (2014) Determinants of low antenatal care services utilization during the first trimester of pregnancy in southern benin rural setting. Universal Journal of Public Health 3(5): 220-228.

17. Mekdes K, Tarekegn T, Teklemariam G, Tariku M, Haregwein Y, et al. (2015) Timing of first antenatal care visit and associated factors among pregnant women attending anatal clinics in Halaba Kulito governmental health institutions. J Women's Health Care 5: 308.

18. Feijen E (2012) Determinants of late and inadequate use of prenatal healthcare in high-income countries: a systematic review. Eur J Public Health 22(6): 900-914.

19. Muluwas A, Muluemebet A, Misra A (2015) Utilization of antenatal care services and influencing factors among women of child bearing age in assosa district, Benishangul Gumuz regional state, west Ethiopia. Global Journal of Medical Research 15: 2.

20. Kyei N, Campbell O, Gabrysch S (2012) The influence of distance and level of service provision on antenatal care use in rural Zambia. PLoS ONE 7: 10 . 
This work is licensed under Creative Commons Attribution 4.0 License

DOI: 10.19080/CTBEB.2018.15.555904
Your next submission with Juniper Publishers will reach you the below assets

- Quality Editorial service

- Swift Peer Review

- Reprints availability

- E-prints Service

- Manuscript Podcast for convenient understanding

- Global attainment for your research

- Manuscript accessibility in different formats ( Pdf, E-pub, Full Text, Audio)

- Unceasing customer service

Track the below URL for one-step submission https://juniperpublishers.com/online-submission.php 